\title{
Review Article \\ Recent Developments in Multiscale and Multiphase Modelling of the Hydraulic Fracturing Process
}

\author{
Yong Sheng, ${ }^{1}$ Marina Sousani, ${ }^{1,2}$ Derek Ingham, ${ }^{2}$ and Mohamed Pourkashanian ${ }^{2}$ \\ ${ }^{1}$ School of Civil Engineering, University of Leeds, Leeds LS2 9JT, UK \\ ${ }^{2}$ Energy Technology and Innovation Initiative (ETII), University of Leeds, Leeds LS2 9JT, UK \\ Correspondence should be addressed to Yong Sheng; y.sheng@leeds.ac.uk
}

Received 9 December 2014; Revised 6 July 2015; Accepted 12 July 2015

Academic Editor: Xiaoying Zhuang

Copyright (c) 2015 Yong Sheng et al. This is an open access article distributed under the Creative Commons Attribution License, which permits unrestricted use, distribution, and reproduction in any medium, provided the original work is properly cited.

\begin{abstract}
Recently hydraulic fracturing of rocks has received much attention not only for its economic importance but also for its potential environmental impact. The hydraulically fracturing technique has been widely used in the oil (EOR) and gas (EGR) industries, especially in the USA, to extract more oil/gas through the deep rock formations. Also there have been increasing interests in utilising the hydraulic fracturing technique in geological storage of $\mathrm{CO}_{2}$ in recent years. In all cases, the design and implementation of the hydraulic fracturing process play a central role, highlighting the significance of research and development of this technique. However, the uncertainty behind the fracking mechanism has triggered public debates regarding the possible effect of this technique on human health and the environment. This has presented new challenges in the study of the hydraulic fracturing process. This paper describes the hydraulic fracturing mechanism and provides an overview of past and recent developments of the research performed towards better understandings of the hydraulic fracturing and its potential impacts, with particular emphasis on the development of modelling techniques and their implementation on the hydraulic fracturing.
\end{abstract}

\section{Introduction}

Hydraulic fracturing, or fracking, is a technique used in the mining industry and involves the controlled cracking of the rock formation with the use of high pressure liquid fluids [1]. The technique of hydraulically fracturing the rocks has been well known since it has been widely used for Enhanced Oil Recovery (EOR) and Enhanced Gas Recovery (EGR) in the oil and gas industries, especially in the USA, to extract more oil/gas through the deep rock formations $[2,3]$. Hydraulic fracturing is a combination of processes, such as the deformation of the formation due to an external mechanical load (i.e., fluid pressure), the fluid flow through preexisting cracks of the formation, and the propagation of cracks $[4,5]$. While the technology behind these processes has been used for more than 30 years in the name of energy exploitation, underground formations constitute a complex system of variables (both rock and well properties) that are not fully understood and thus are still under investigation $[6,7]$.
Scientists over the years have concluded that there is a clear relationship between the increase of $\mathrm{CO}_{2}$ and human activities [8-10]. Overpopulation and therefore extensive industrial activities contribute greatly to the increase of greenhouse gas emissions and countries have agreed to a common mitigation plan in order to reduce the $\mathrm{CO}_{2}$ emissions to acceptable levels and achieve a low carbon energy future [9, 11-14]. Carbon Capture and Storage (CCS) is a promising method that plays a central role as part of the mitigation plan $[10,15-18]$. CCS is a five-step procedure which embraces all stages of industrial production [19]. Specifically, it involves the capture of high amounts of $\mathrm{CO}_{2}$ produced from industrial facilities before they are released into the atmosphere, its liquefaction and pipeline transport into the site (oil and gas reservoirs, saline formations), injection under high pressure, and storage in deep underground formations [20]. Figure 1 illustrates all stages of the CCS technology from capture until storage. The hydraulic fracturing technique on porous media has become part of the injection and storage stage of CCS $[1,21]$ and therefore it is essential to 


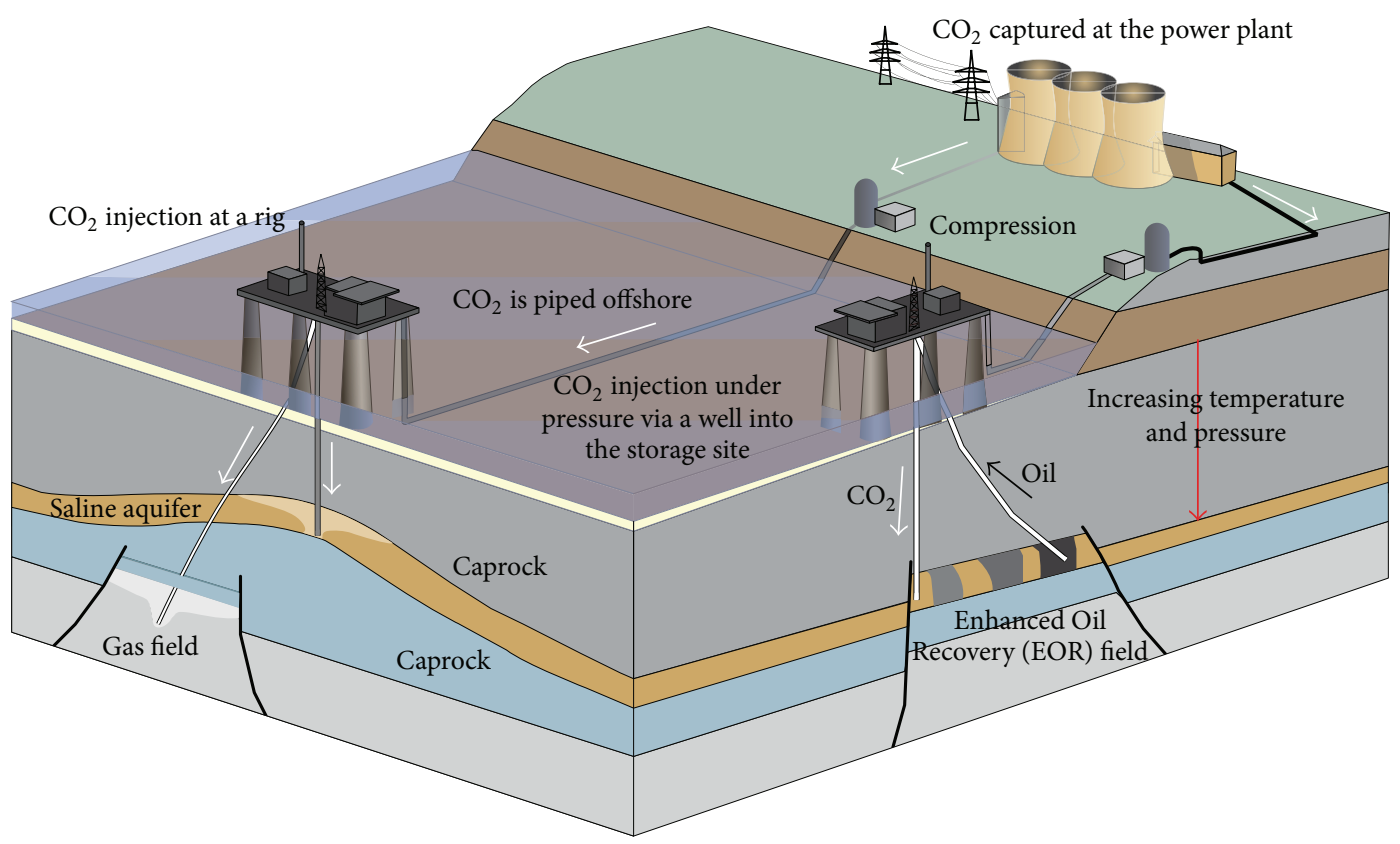

FIGURE 1: Schematic of CCS infrastructure showing the five steps of the technology and the geological media of storage [137].

understand the mechanisms that involve permanent storage and reduction of $\mathrm{CO}_{2}$.

The economic benefits from energy exploitation and especially the extraction of natural gas from shale gas formations through hydraulic fracturing methods are estimated to be considerable. The USA has already moved towards extensive shale gas exploitation, making Europe the next one to follow in the search of energy production and economy growth. Specifically, in the UK there are some promising estimations of the amount of shale gas from numerous formations throughout the nation. According to the British Geological Survey (BGS) and the Department of Energy and Climate Change (DECC), the Bowland Shale formation is estimated to contain about 1300 trillion cubic feet of shale gas, with about 10 per cent recoverable [22]. The scenario for UK shale gas production looks to be more encouraging, according to the Institute of Directors (IoD), suggesting high investments and numerous jobs [23], while suggesting considerable reductions of imported gas (around 37 per cent) in terms of consumption until 2030, which may lead to further reductions of the import costs, assisting towards a more balanced economy and energy security [24]. However, it is important to add that the economic implications are under speculation since they are based mostly on estimations, inferred from the US experience, and not on actual production.

\section{Enhanced Oil and Gas Recovery}

Enhanced Oil Recovery (EOR) and/or Enhanced Gas Recovery (EGR) is regarded as the most effective schemes for a low carbon energy future, since $\mathrm{CO}_{2}$ injection and oil/gas extraction from hydrocarbon reservoirs can be performed concurrently [25]. During this process, fluids are injected under high pressure into porous formations, with the aim of storing the liquefied $\mathrm{CO}_{2}$ under an impermeable caprock, and cause controlled cracking to improve reservoir productivity [7]. Figure 2 illustrates a hydraulic fracturing technique in a shale gas formation, where the fracturing fluid is injected within the shale under high injection pressure to reactivate or open new fractures into the formation. The fractures stay open with the use of shale proppants (sand or ceramics) so that the shale gas can travel towards the well [26].

Between the two methods, EGR is relatively new and is still under investigation. The main reason is the concerns for degrading gas production due to the mixture between the initial gas in place and the injected $\mathrm{CO}_{2}$ [27]. Furthermore, ongoing research aims to provide further insight into such matters, focusing on investigating the factors that affect the process of EGR and storage. Such an example is the work by Khan et al. [28], who replicated a 3-dimensional reservoir sandstone model using actual experimental data and simulated an EGR process, while sequestrating $\mathrm{CO}_{2}$. Their findings refer to that one specific reservoir and can confirm that the $\mathrm{CO}_{2}$ injection is applicable in increasing natural gas recovery and storing high amounts of $\mathrm{CO}_{2}$ at the same time. The conventional procedure of oil extraction involves the injection of water; however, a large amount of oil stays trapped within the pores of the formation (about 50 per cent) after the primary production, and further recovery can be achieved by injecting liquefied carbon dioxide [29]. The latter exists in a supercritical state (dense phase fluid), with reduced viscosity $(0.04-0.08 \mathrm{Cp})$ and surface tension, which means that the vapour and liquid forms of the $\mathrm{CO}_{2}$ coexist. The component acts like a gas and a compressible fluid at the same time and can take the shape of its vessel, while having a density (about $600-800 \mathrm{~kg} / \mathrm{m}^{3}$ ) like a fluid [27]. This supercritical state is achieved at depths above $800-850 \mathrm{~m}$, 


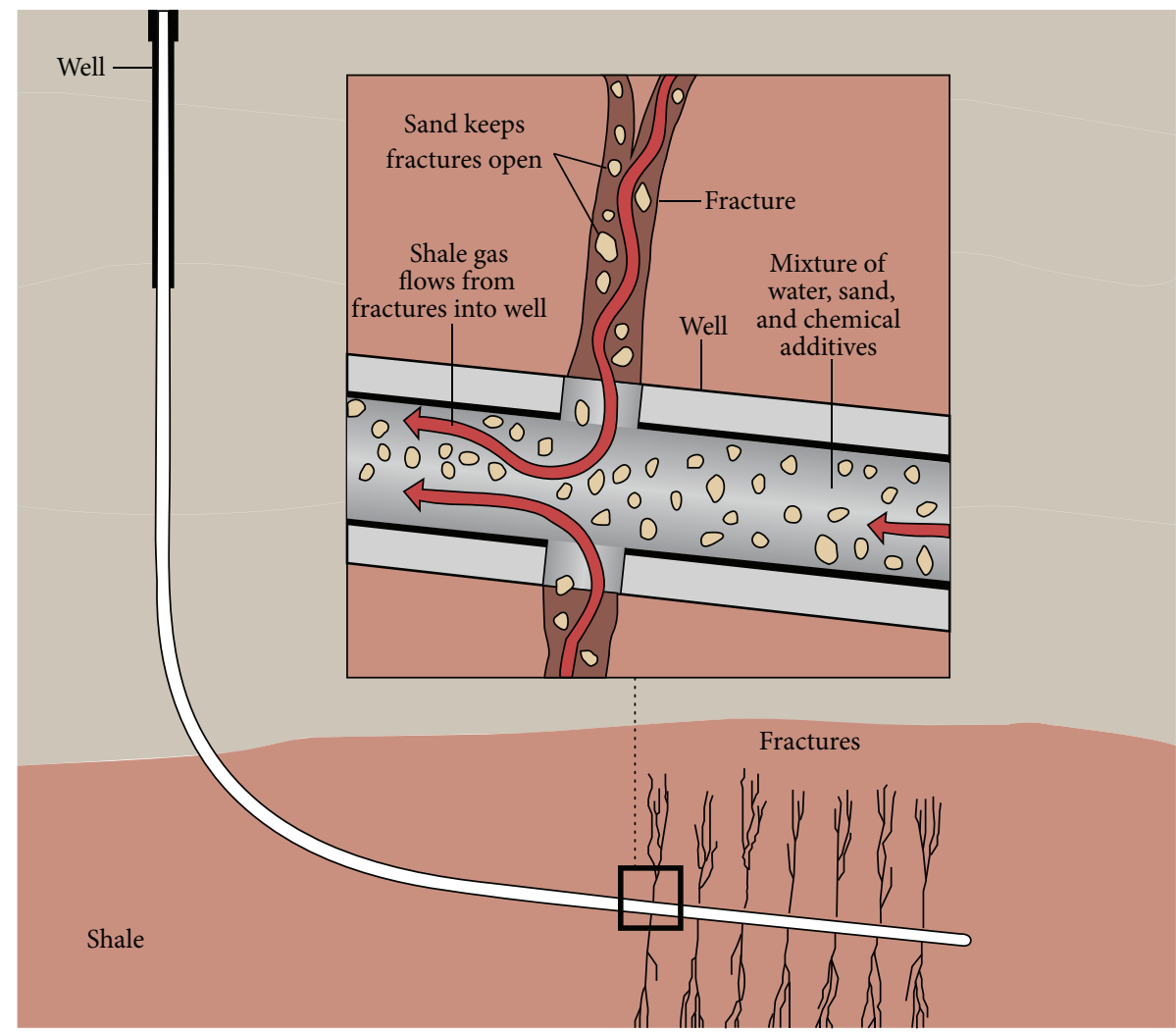

FIGURE 2: Schematic of the hydraulic fracturing technique in a shale gas formation [138].

pressures beyond $7.38 \mathrm{MPa}$, and temperatures higher than $31^{\circ} \mathrm{C}$, respectively [25]. Due to the dense phase and the fact that it is easily miscible with other oils, it gives the $\mathrm{CO}_{2}$ great potential to dissolve and relocate the oil in the reservoir. This technique is a key technology to reduce the anthropogenic emissions produced from overpopulated regions, such as China, while satisfying the extensive demands on electricity [30]. Although hydraulic fracturing is part of the technology used for gas/oil extraction, and thus widely used, it is still lacking the development of appropriate regulations for environmental safety and sustainability.

\section{Hazards in Hydraulic Fracturing}

Regardless of the choice of liquid (water or liquefied $\mathrm{CO}_{2}$ ), the hydraulic fracturing process requires the use of a considerable fluid pressure in order to introduce the liquid into the rock formation, until it exceeds the overall strength of the rock (both compressive and tensile) [31]. Therefore, valid estimates of the mechanical behaviour of the rock material under intense injection conditions are crucial to the efficient planning and operation of hydrocarbon reservoirs. This constant increase in the fluid pressure during injection causes redistribution of the in situ effective stresses within the reservoir. Although in this process the controlled fracturing of the reservoir is desirable, such stress changes may induce irreversible effects into the rock strata, thus causing possible reactivation of the existing faults. Moreover, the effects of active faults on the process of leakage are an area where more research has to be performed; scientists generally suggest that the existence of seismogenic faults affects the permeability structure of the zone enhancing fluid transport [32]. In the process of hydraulic fracturing, the latter may lead to possible leakage of liquefied $\mathrm{CO}_{2}$ [33] or flowback water, thus resulting in potential hazards. Moving towards a bigger picture, the major effects are the possible contamination of shallow groundwater layers by the migration of the toxic components of the flowback fluids as well as the leakage of methane, which acts as a greenhouse gas, into the atmosphere [34].

3.1. Flowback Fluid. Flowback fluid is the recovered fracturing fluid after the pressure release and the extraction phase and it mainly consists of a formation fluid and hydraulic fracturing fluid (fluid, proppants, and chemical additives). The key point is that the flowback fluid differs from the initial fracking fluid that was used during injection, with respect of composition. The majority of the volume of sand and proppants stays trapped within the pores of the formation, while the chemical additives react due to intense injection conditions, such as high temperature, resulting in reaction products. Therefore there is a potential risk of contamination of freshwater resources if flowback fluid is allowed to flow uninhibitedly. The exposure of the chemicals of the fracking fluid and the risk to groundwater reserves are linked to factors including underground or aboveground accidents 
during transport and the concentration/handling of the possible hazardous substances [35]. Currently, the issue of potential implications on the quality of water is a matter of debate. This is due to lack of available information on the composition of the chemicals used in hydraulic fracturing procedures, and therefore scientists focus on this part of research aiming to shed more light. Recent studies are dealing with the ecotoxicological assessment of undiluted fracturing fluids, which indicate a hazardous effect on aquatic life. These studies are based on component-based prognostic models rather than measuring the ecotoxicological effect of a fracturing fluid as a whole [36]. This provides better accuracy of the overall results, allowing the prognosis of the effect of the mixture components individually. Generally, flowback fluids contain a mixture of hydraulic fracturing fluid and formation water. The potency of flowback fluid depends on the mix ratio of the formation water and fracturing fluid and although a high proportion of the fracturing fluid may be retained in the formation there is a high tendency for flowback to take place as a result of imposed fracturing operations [37]. At present, very limited studies have dealt with the chemical composition of flowback or its potential pollutants, and there are no studies investigating the difference in fracturing fluid from formation water that contains no fracturing fluid in flowback. The work performed by Olsson et al. [37] aims to bridge the knowledge gap by analysing the composition and volumes of flowback from different sites in Germany. This research has revealed that no single technology can meet the criteria for the overall treatment of flowback; thus they categorized the flowback fluid into groups and suggested some treatment methods. Furthermore, the accidental penetration of the fracturing and flowback fluids into the water aquifers and their impact on the human-health becomes critical and has been addressed recently. Such an example is the work by Gordalla et al. [35] who focused on the assessment of the ingredients of the fracturing fluids on the human-toxicological point of view, the influence of the flowback, and the possible hazards of freshwater reserves and suggested methods for minimising the environmental impact. Moreover, apart from the importance of extending the available information on the chemical composition of fracturing fluids or the environmental impact of the flowback and its proposed treating methods, it is of equal importance to investigate the underground formations and their interaction with the potential migrating fracturing fluids or methane. Such an example is the work by Lange et al. [38] who aimed to identify fault zones as preferential pathways that facilitate the movement of fracturing fluids/methane in unconventional gas reservoirs and analysed the effectiveness of the different layers of overburden.

3.2. Risk of Contaminated Aquifers. The extensive use of unconventional fracking (horizontal drilling and high volume hydraulic fracturing), especially in the USA, has triggered a public debate regarding possible health issues related to drinking water. Although industry claims that shale gas fracking is safe with minimum environmental impacts, the European Commission states that the extraction of unconventional hydrocarbons (shale gas) generally imposes a larger environmental footprint than conventional gas extraction [39]. Risks from ongoing operations may include surface and groundwater contamination, water resource depletion, air and noise emissions, land take, disturbance to biodiversity, and impacts related to traffic. People's concern, especially in European countries where groundwater is their main resource of drinking water, has forced countries to seek expert opinion. A typical example is Germany and the ExxonMobil initiative [40]. The latter has formed a multidisciplinary working group in order to identify the possible environmental risks for the Lower Saxony Basin. Their main task is to assess the available technology (drilling and technical processes) and develop a strategy that fits the requirements for safe hydraulic fracturing operations. Part of this assessment is the "information and dialogue process on hydraulic fracturing," focusing on the characterization of the hydrogeological system, the chemical reactions under which leakage may occur, the possible leakage pathways, and the development of suitable models and their results $[34,38]$.

\section{Modelling of Rock Fragmentation and Fluid Flow Problems}

Moreover, the rapid growth in computer power and modelling has resulted in the development of a large number of software packages used for the numerical analysis of complex engineering problems, such as the identification of problematic (low bond strength) material parameters in masonry structures [41]. The reason for this is that it is very difficult for the analytical modelling to measure and describe accurately the complicated problems associated with fracturing. In subsurface investigations in particular, where heterogeneity and a wide range of complex inner mechanisms coexist, numerical modelling is necessary to represent real life scenarios. Numerous mathematical solutions have been applied to look, for example, into the critical mechanical parameters, such as the stress envelope, the porosity and permeability of the material and the effect of layering within the rock, or the way that these are influenced by the external mechanical load [42]. However, studies that employ modelling and simulation of rocks at the microscale [4345] are fewer and their focus on the complex interplay between the microproperties and their corresponding effect on the material's behaviour during the calibration procedure provides at best a general guidance. Therefore, a review on the micro-meso-level modelling using Discrete Element Method is first provided in this section to highlight the research progress in recent years in this area, followed by the broader overview of multiscale and multiphase coupling models.

4.1. Discrete Element Methodology. The DEM is an alternative approach, to the Finite Element Method (FEM), which aims to describe the macroscopic mechanical behaviour of materials as a result of the interaction of its constitutive individual elements. Specifically, in DEM the material is described as a discontinuum, consisting of numerous distinct particles which represents the inhomogeneities within the material (joints and/or fractures) in the particle scale $[45,46]$. Initially particle scale models were developed in order to simulate the 
behaviour of soils and sands (noncohesive materials) [47]. The transition from the aforementioned modelling to the one that simulates the micromechanical behaviour of solid rocks is commonly known as the bonded particle model (BPM) for rock [45]. In a BPM, the breakage of interparticle bonds simulates the nucleation of a microcrack, while microcracking is achieved by coalescence of multiple bond breakages. The DEM methodology and the particle-based models have been employed in several computer packages in the field of rock mechanics, such as the particle flow code (PFC), the YADE, the universal distinct element code (UDEC), and the discontinuous deformation analysis (DDA).

The advantages of the DEM methods over other traditional techniques, such as the Finite Element Method (FEM), are the simpler representation of the geometries of real rocks, which contain discontinuities, the easier simulation of complex engineering problems without the use of complicated constitutive equations, and thus provide statistically more accurate results. Conversely, the increased simplification requires extensive experimental validation to verify the numerical results of the method and proves that the microscopic models can produce equivalent macroscopic behaviour of real rocks. Finally, the increased computational time due to the nature of the DEM approach (solving the governing equations for a large volume of particles) is another limitation that researchers have to tackle.

4.1.1. Particle Flow Code (PFC). Each of these approaches is based on the DEMs governing formulations, which include the calculation of the relative motion of the discrete elements, such as slip, rotation, or even complete detachment. More specifically in PFC each particle's motion is calculated by the equation of motion, given by

$$
F_{i}+F_{i}^{d}= \begin{cases}m \ddot{x}_{i}, & \text { for } i=1,2,3, \\ \dot{I} \omega_{(i-3)}, & \text { for } i=4,5,6,\end{cases}
$$

where $F_{i}$ is the generalized force which includes the gravitational force, $F_{i}^{d}$ is the damping force, $m$ is the particle's mass, $\ddot{x}_{i}$ is the particle's translational acceleration, $I$ is the moment of inertia, and $\dot{\omega}$ is the angular acceleration.

For the cases where the virtual particles are connected with bonds (reproducing the cementation between grains in real rocks), the updated body forces and moments, due to the presence of bonds, are calculated via the force displacement law:

$$
\begin{gathered}
F_{i}^{T}=F_{i}^{n}+F_{i}^{s}, \\
M_{i}^{T}=M_{i}^{n}+M_{i}^{s},
\end{gathered}
$$

where $F_{i}^{T}, M_{i}^{T}$ are the total force and moment vectors and $F_{i}^{n}, F_{i}^{s}, M_{i}^{n}$, and $M_{i}^{s}$ are the axial and shear components with respect to the contact plane, respectively. Details on the PFC calculation cycle based on the DEM can be found in Sousani et al. [48]. However each approach has its own limitations. The PFC utilises the BPM model, since the parallel bond rock modelling has been widely used to simulate the fracturing mechanism in brittle rocks, but previous versions had the disadvantage of unrealistic ratios between the obtained tensile and unconfined compressive strength, to low nonlinear failure envelopes in terms of triaxial tests, or the problematic modelling of the interfaces due to the inherent roughness of the interface surfaces [49]. To tackle these limitations of PFC, a number of enhancement measures have been developed with the aim of providing a more accurate nonlinear mechanical behaviour, strength ratios, and friction coefficients. The basic concepts include the "cluster logic" (bonded particles packed together to form angular shapes or blocks that resemble natural grain structures, Figure 3(a)), performed by Potyondy and Cundall [45], the "clump logic" (bonded particles that behave collectively as a single unbreakable rigid body, Figure 3(b)) from Cho et al. [50], the flat-joint contact model (a more efficient contact formulation, where disk-shaped particle contacts simulate a finite-length interface that has relative rotation, even upon bond breakage, Figure 3(c)) from Potyondy [51], and finally the smooth-joint contact model (SJM) and the synthetic rock mass approach (SRM), respectively, from Mas Ivars [52, 53].

The SJM model simulates the behaviour of an interface disregarding the particle contact orientations locally alongside the interface, while the SRM model is a combination between the BPM and the SJM models that describes the mechanical behaviour of jointed rock masses, including anisotropy, brittleness, and scaling effects which cannot be achieved by empirical methods.

4.1.2. Open-Source Software YADE. Recently, another particle-based code has been developed, called YADE, as an alternative approach to the well-known commercial PFC code as previously described $[54,55]$. YADE aims to be more flexible by adding new modelling capabilities, several simulation methods (e.g., DEM, FEM, and Lattice Geometrical Model (LGM)) can be coupled within the same framework and also the scientific community can provide direct feedback for improvement of the code with the use of an open-source platform. The fundamental principles of YADE are similar to those of PFC with respect to small deformations and fracturing (linear elastic interparticle forces and bond breakage, resp.) but new features, simulating rock discontinuities and ensuring frictional behaviour regardless of the inherent roughness, have been implemented as an alternative approach to the SJM and SRM models [56]. In addition, the use of YADE in studying the failure of brittle rocks has led to the creation of additional features, such as the interaction range coefficient, which helps to accurately simulate high ratios of compressive to tensile strengths as well as nonlinear failure envelopes [57]. However, YADE as well as many of the open-source software packages appear to be inefficient when compared to commercial software such as PFC, mainly due to the complexity of the user's interface and the lack of user defined functions. Moreover, open-source software solutions tend to develop mainly in line with specific purposes and also rely on the pool of open resources to help to discover errors and bugs. Some applications of the YADE code include three-dimensional simulations of the progressive damage in fractured rock masses [56], or the 


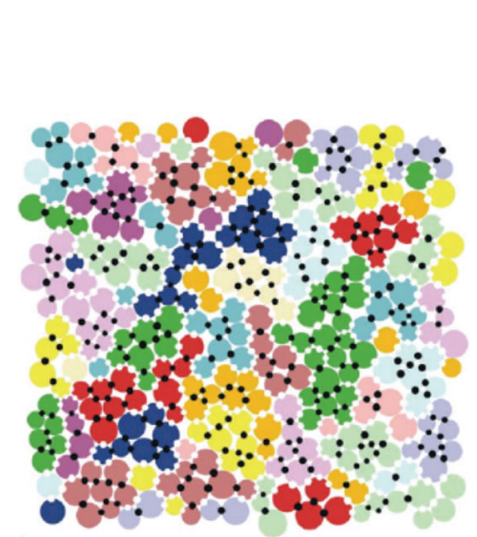

(a)

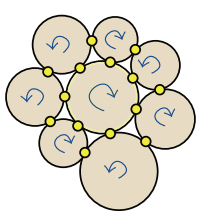

Clustered particles

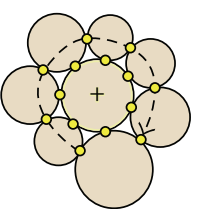

Clumped particles

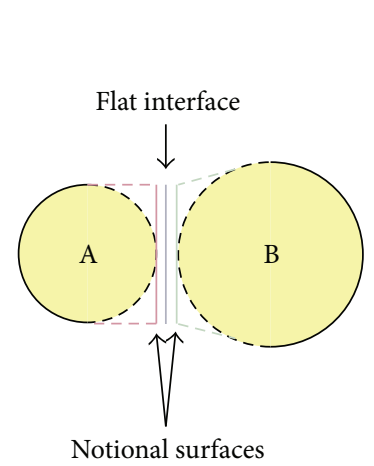

Notional surfaces

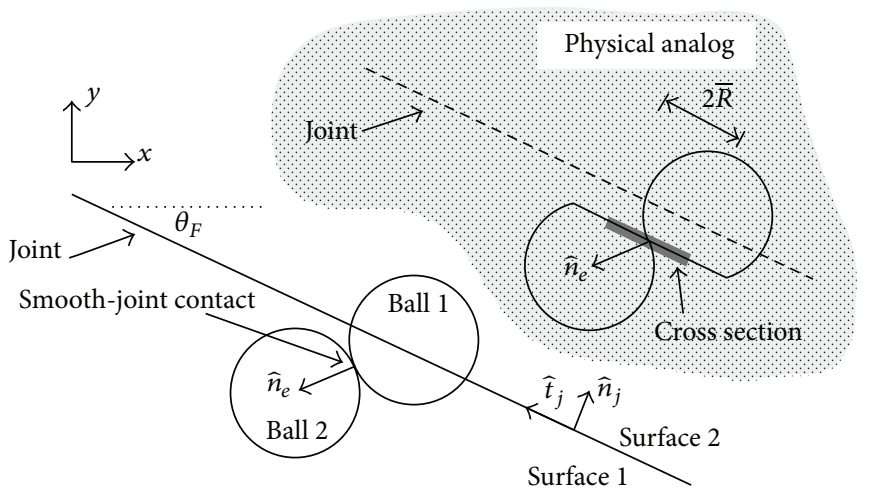

(c)

FIGURE 3: Developments on the BPM model for better representation of the nonlinear behaviour of hard rock and more realistic values of the ratio between tensile and unconfined compressive strengths. (a) The "cluster" logic [45], (b) the "clump" logic versus the "cluster" logic [50], (c) the flat-joint contact model [51], and smooth-joint contact model (SJM) [139].

effect of preexisting fractures of the brittle materials, under triaxial loading, on their mechanical behaviour $[58,59]$. In the aforementioned simulations the open-source code YADE has been collaborated with the Discrete Fracture Network (DFN) in order to model the three-dimensional structure of the discrete features.

\subsubsection{Universal Distinct Element Code (UDEC). Another type} of modelling, which is based on the DEM equations, is the UDEC, employed to study rock masses that contain numerous fractures $[60,61]$. The computational domain in UDEC is quantized into blocks using a finite number of intersecting discontinuities and each block is discretized with the use of a finite difference scheme in order to calculate stresses, strains, and deformation. The basic limitation of this technique was the fact that the failure mechanism in rocks was described either through plastic yielding or through deformation of preexisting fractures. Therefore new fractures could not be modelled and hence fracturing of intact rocks was impossible. This limitation was addressed by Lorig and Cundall [62] who introduced a polygonal block pattern into the modelling and enhanced UDEC's simulation capability. UDEC is a relatively new approach to rock failure and thus verifications and improvements of the code are some of the required tasks of experts in the field. Applications of the code can be found on modelling of the triaxial tests of the lithophysal rock samples, where the laboratory triaxial testing is considered almost impossible [63]. Extended results of this study on the same rock material, with the use of the UDEC, are presented by Damjanac et al. [64] who focused on the mechanical degradation of the behaviour of the material. An upscaled version of the developed model was employed to investigate the stability of the drifts from the region (Yucca Mountain) considering the in situ thermal and seismic loading as well as the time-dependent degradation.

4.1.4. Discontinuous Deformation Analysis (DDA). Finally, the DDA is a method also based on DEM but with similarities with the Finite Element Method (FEM) and was originally introduced by Shi and Goodman [65]. DDA is employed to simulate the stress, strain, sliding, and detachment/rejoining of systems containing rock blocks. Similarly to the FEM, the basic structure of the method, in terms of formulations, contains linear equations which results from differentiating and minimizing each energy contribution to the system. Improvements of the method have been employed over the years with the latest work being performed by Tang and $\mathrm{Lu}$ [66]. They combined the DDA method with the Rock Failure 
Process Analysis (RFPA) software, the latter based on continuum mechanics [67], to investigate large scale deformations of discontinuous rock systems using the capability of RFPA to capture small deformation, crack initiation/propagation, and coalescence in intact rocks.

4.2. Combined FEM/DEM and Other Hybrid Techniques. The FEM and its improved approaches are considered a standard technique that can be successfully applied to numerous problems, such as the modelling and evaluation of rock materials or rock failure with internal discontinuities [68-70]. An example of a FEM is the two-dimensional finite difference programme FLAC [71]. This programme is employed to investigate the behaviour of materials such as soil and rocks and more specifically it simulates soil and rock structures that may undergo plastic deformation once their maximum yield limits have been reached. FLAC users create a grid, which consists of elements and zones, which fits the shape of the sample to be modelled. However, due to its geometric limitations, more discretization methods have been developed to address its difficulties, such as the extended Finite Element Method (XFEM) [72] for computing the three-dimensional crack propagation [73, 74], specifically focusing on the improvement of meshing sensitivity employed to compute the fragmentation problems [75]. A number of hybrid techniques have been developed based on the FEM with DEM implementations. This combination is called the hybrid continuum-discontinuum method or the combined FDEM and includes models such as the ELFEN (Finite Element/Discrete Element System) [76] or the Y-Geo software [77, 78] which are based on the Finite Element Method to describe the solid part of interest but also adopt the theory of the Discrete Element Method. The concept in FDEM is the transfer from continuum to discontinuum through fragmentation. Specifically, the sample's matrix is modelled with the use of continuum mechanics and as the test progresses the equations of motion are integrated. Then the initiation of cracks/fragmentations is such that it satisfies suitable fracture criteria, which therefore leads to the formation of new individual discrete bodies. Comparing the FDEM with the FEM and the DEM, respectively, we can claim that it is more capable of capturing the behaviour of postrock fragmentation and also it is more flexible in modelling deformable and unique-shaped particles. Furthermore, between the two modelling techniques, the Y-Geo approach resembles more a discrete method. Specifically, the representation of a sample with the use of Y-Geo is closer to a particle-based model, where the particles and their bonds are replaced by deformable triangle elements and four-noded cohesive elements [77], whereas in ELFEN a transfer between a continuous elastoplastic sample and a sample with discrete fractures is achieved by importing cracks into the sample [79].

4.3. Modelling of Fluid Flow in Hydraulic Fracturing. A wide range of engineering problems could utilise the DEM approach coupled with fluid models to analyse the fracking process within the rock specimen [21] or the influence of the significant parameters, such as the injection pressure, to a successful injection/storage application [80]. Also it is used to simulate the behaviour of materials such as sandstone and limestone and the fluid-solid interactions among them [45, 81]. Initially, the fluid-solid interactions were described by the lattice Boltzmann method, which computes the fluid flow and solves the discretised form of the Boltzmann equation, based on the Navier-Stokes equation [82]. Other methods for computing the fluid flow include Direct Numerical Simulation (DNS) $[83,84]$, where the flow variables (e.g., pressure and velocity) exist as a function of space and time and can be obtained from the numerical solutions of the Navier-Stokes formulations, and Computational Fluid Dynamics (CFD). However, the need to provide linkages between the coexisting fluid and the solid phases necessitates a coupling of these techniques with the modelling of the solid phase, such as the DEM. The lattice Boltzmann and the DEM coupling have been described in detail by Boutt et al. [85], while approaches that incorporate CFD with the DEM have been presented in the work by Tsuji et al. [86] and $\mathrm{Xu}$ and $\mathrm{Yu}$ [87]. In their work, the interaction between the solid and gas phases in a fluidized bed has been modelled by solving Newton's second law of motion, with respect to the motion of particles, and the Navier-Stokes equation with respect to the motion of the gas. Most of these coupling schemes are applied to granular or uncohesive materials and in cases where the domain is dominated by fluid phases. Therefore, phenomena such as the deformation of the solid material and fracturing are not captured due to either the limitations in the coupling technique or the delineation of the study.

\section{Developments on Modelling of Hydraulic Fracturing and Engineering Applications}

Understanding the behaviour of the underground rock formations is itself a complex subject and it has been investigated by several researchers in the past [88-90]. The complexity of the hydraulic fracturing technique has resulted in more challenges in this area. There was extended ongoing research, both theoretical and experimental, in an attempt to understand the phenomena involved [45, 85, 89, 91-94]. Several models have been developed focusing on rock mechanics and the modelling of fractures; such an example can be seen in Zhuang et al. [95, 96], where 2D and 3D modelling of a fracture using a meshless method have been developed in order to provide stress analysis and describe the crack evolution or the study of cohesive crack models [97]. The motivation behind the extended modelling researches is that they can be applied to solve some large scale engineering problems; such an example is the investigation of rock stability and rock failure (joints in rock masses) near hydropower stations [98].

Recent developments also focused on the behaviour of hydraulically pressurized intact rocks in the micro or mesoscale [44, 99-101]. Such an example is the work by Marina et al. [43], who replicated a hydraulic fracturing test in a laboratory, and was performed on a thick-walled hollow cylinder limestone rock sample. The work studied the mechanical behaviour of the limestone sample under fluid pressure differential and the comparison between the fracturing pattern of the virtual model and the laboratory rock sample. The modelling of the rock and the analysis 


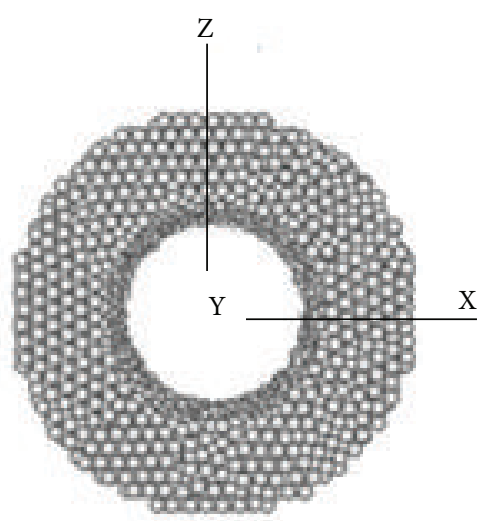

(a)

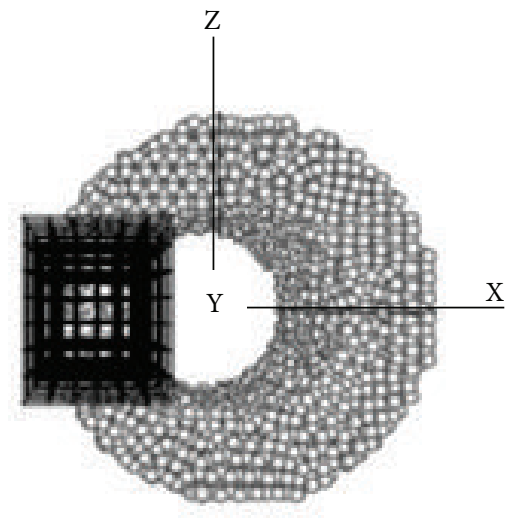

(b)

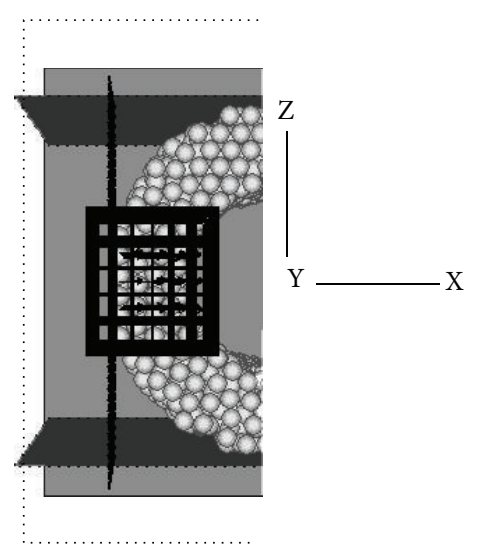

(c)

Figure 4: (a) Schematic of the virtual limestone model with the use of the DEM approach, (b) application of the fluid cell grid around a slice of the sample, and (c) fluid velocity vectors indicating the horizontal fluid movement from the outside surface towards the hollow core [43].

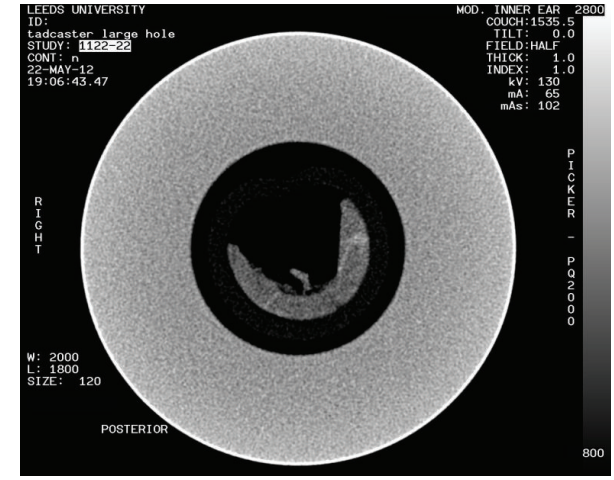

(a)

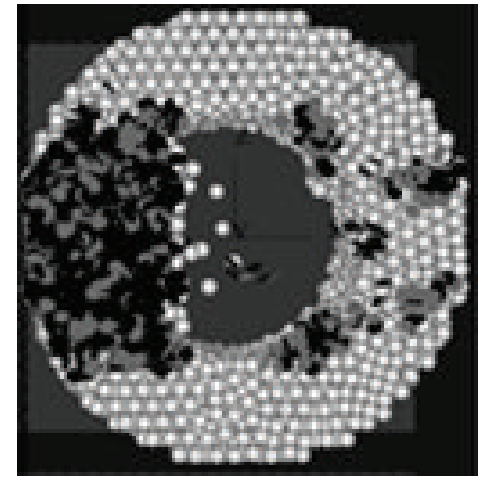

(b)

FIGURE 5: (a) Scan image of the limestone specimen inside the test tube at the moment of collapse (35 MPa) of the cavity wall and (b) microcracking of the virtual assembly at the moment of collapse (32.3 MPa) [43].

of the fracturing mechanism were performed with the use of the DEM approach (Figure 4(a)). The particles were bonded together with parallel bonds (adopting a springlike behaviour), where each contact point has a maximum tensile strength in the normal direction and maximum shear contact-force strength due to the contact bond. Therefore, every time either the calculated maximum tensile or shear force exceeds the tensile or shear strength $\left(\sigma_{\max } \geq \bar{\sigma}, \tau_{\max } \geq\right.$ $\bar{\tau}$ ) of the spring (bond), the parallel bond breaks and this results in a microcrack. Furthermore, the simulation of the fluid flow was performed with the use of fluid cells that encapsulate the region of interest and provide measurements, as shown in Figures 4(b) and 4(c).

The numerical results were validated by Lame's theory and were also found to be in very good agreement with the experimental results. They also captured the fracturing pattern within the rock samples induced by the hydraulic pressure (Figure 5).

A similar study in the particle scale has been conducted by Al-Busaidi et al. [102], who investigated the initiation and propagation of hydrofractures as well as the resulting seismic output and compared these results with experimental data produced from other scientists. Generally, their approach can replicate most of the observations from the hydrofracturing experiments. More specifically, the numerical modelling was two-dimensional and part of the study used a number of homogeneous samples. The numerical results demonstrated some consistencies with the experimental results, showing a damage pattern along the potential macrocrack track. Another example is the work by Wang et al. [103], who simulated a hydraulic fracturing process of a coal seam and analysed the relation between the macroscopic and the mesoscopic mechanical parameters of the material. They focused on the influence of the mechanical properties in the macroscale to the initiation and the size of cracks, the empirical calculation of the breakdown pressure, and the analysis of the crack propagation due to the injection conditions. They compared their results with data derived from field observations.

The basic intention of the fracking process is to maximise the reservoir's permeability, but the permeability of a fractured formation is highly affected by the openings of 
the fractures. However, the fractures tend to close after a hydraulic fracturing operation and thus suitable proppants have to be selected, blend in a certain ratio with the fracturing fluid, fill the fractures, and keep them open after fluid injection [2]. Therefore estimation of the residual openings $[46,104,105]$ or the permeability of the fracture openings [106], which are filled with proppants, as well as the optimisation of the used proppants [107] is of great significance for EGR/EOR applications. A number of studies have focused on the transport of suspended proppant particles within the fracture and the interaction between the formation and the proppant. Specifically Deng et al. [26] investigated the shaleproppant interactions and evaluated the fracture aperture under the influence of different pressure levels, proppant sizes, and Young's modulus of the shale. According to their findings, the softer is the shale particle; then the larger is the pressure and the proppant suggesting a smaller crack opening and larger plastic zone for other given conditions.

\subsection{Direct Applications of Hydraulic Fracturing Studies. Other} studies have focused on large scale numerical modelling and the observation of the behaviour of substantial formations. The work by Mas Ivars et al. [53] is an example of a large scale 3D modelling approach (10 up to $100 \mathrm{~m}$ ), obtaining a qualitative and quantitative understanding of the mechanical behaviour of the rock formation both before peak and after peak. They used the synthetic rock mass (SRM) approach which is based on the bonded particle model (BPM) for rock and the smooth-joint contact model (SJIM) in order to replicate the intact rock and the in situ join network, respectively. However, due to the nature of their study, factors that affect the behaviour of the formation in the particle scale, such as the grain size, the porosity, and the pore structure, were not considered. Other studies have dealt with the simulation of seismic events, produced from fluid pressure distributions, on large scale reservoirs $(2 \times 2 \mathrm{~km})$ with the use of discrete particle joints models [108]. Furthermore, many rock engineering projects, such as mining or exploitation of geothermal energy resources, are directly related to drilling and thus fracturing, which drives research towards the investigation of the wellbore instability for hard and low porosity sedimentary rocks [109]. Fundamental and numerical analysis, such as the work performed by Zhang et al. [110] and Marina et al. [43], were developed to deal with the effect of rock geometry and various pressure differentials on the wellbore instability. Comparisons of the numerical results towards analytical solutions and experimental data provide a better understanding of the behaviour of the material and the propagation of cracks in both mesoscopic and large scale rocks. Furthermore, factors such as measurements of the minimum in situ stress and permeability are significant for the design of hydraulic fractures, which affect several engineering applications, and therefore extended research has been conducted relating the changes in the rock permeability with in situ stresses [111-115] as well as the influence of the in situ stresses to the fracturing pattern (propagation and closure) on pressure sensitive materials [104]. It is significant to observe how individual studies, such as the aforementioned or others related to the influence of stress and deformation on the propagation of hydraulic fractures [116-118], become part of the bigger picture of hydraulic fracturing and can be connected with more recent studies focusing on the use and stability of the proppants in the fractures (as previously discussed). Recently more engineering applications have emerged where the fracking procedure is the dominant part. Examples of such projects are the waste disposal by the injection of slurries, in depths between 600 and $830 \mathrm{~m}$, into appropriate sandstone and shale formations [119] and the production of heat from the hot dry rocks within geothermal reservoirs [120]. Therefore understanding the mechanisms involved in fracking, in order to control and ameliorate the process and maximise its benefits, is essential.

Furthermore, the investigation of groundwater flow under high water pressures and possible groundwater inrush incidents is of high significance especially for the ongoing operations on hydropower stations [121] and in coal mining [122]. The effect of high external water mechanical load and pore pressure is a key issue to the overall stability of the groundwater cavities and thus numerical analysis is essential in order to prevent possible leakage and help assist towards efficient design. The selection of an appropriate method to investigate groundwater flow and simulate pore pressure in fractured masses depends on several parameters, such as the boundary conditions, the scale of the reservoir, and the geological conditions of the area. However, the most popular methods for such analysis include the continuum medium approach [123], the Discrete Fracture Network (DFN), and methods coupling both continuum and discrete media $[121,124]$. However, each individual approach has its own limitations. The continuum medium approach has proven to be inadequate in describing large scale regions since it has to oversimplify the fractured formation as a homogeneous zone [125]. The DFN approach cannot produce the detailed set of the geometrical parameters for individual fractures, while requiring extensive computational time for large scale simulations $[126,127]$. The third approach can be considered more efficient since it combines the advantages of both continuum and discrete methods.

\subsection{Critical Parameters Which Affect the Hydraulic Fractur-} ing Mechanism. The complexity of analysing the hydraulic fracturing further increased by a large number of variables in the process, such as varying material properties (compressive/tensile strength, elastic constants, properties of particles and bonds, etc.), stress boundary conditions, the viscosity of the fracturing fluid, the grain size and permeability of the rock, and the preexisting fractures within the rock's matrix. The majority of the aforementioned variables are currently under investigation; such an example is the work by Sousani and Ingham $[48,128]$ who investigated the effect of the orientation and the number of the samples' preexisting fractures to the cracking mechanism. Some of the observations indicate that in samples containing fractures below $45^{\circ}$ horizontal expansion of the microcracks is gaining ground (along the $\max$ compressive stress), whereas for fractures above $45^{\circ}$ microcracking is observed to extend perpendicular to the max compressive stress. It was also observed that the effect of the confining stress combined with the heterogeneity of 
the material, due to fracture, affects the orientation of the microcracking; finally, it was validated that extensive cracking is directly related to energy release, resulting in an increase of the kinetic energy within the sample.

Another example is the work performed by Martinez [129] who investigated the influence of varying material properties and boundary conditions in the microscale on the fracturing mechanism of poorly consolidated rock formation. Based on his overall results, he suggests that conventional theory ignores the mechanisms, such as shear cracking, which control the propagation of fractures with respect to poorly consolidated rocks and that the assumption of linear elastic behaviour of the material is not always dominant in Discrete Element Method (DEM) simulations. More examples are the work by Shimizu et al. [130-132], who dealt with the effect of the fluid viscosity and the grain size, to the behaviour of the hard rock. They observed that in the case of a homogeneous material and the use of a high viscous fluid the breakdown pressure was much higher than in the case of heterogeneous material. Their findings can be attributed to the defects between grains, due to differences of grain size, which therefore trigger the initiation of fracking. Their results were in agreement with laboratory results $[93,133,134]$ which show a decrease of breakdown pressure with increasing grain size. Also they concluded that when low fluid viscosity was used, the fracture propagated along the direction of maximum compressive stress and the fluid penetrated directly into the fracture. The opposite occurred in the case of high viscosity, where the fluid cannot penetrate into the fracture unless the latter propagates first.

Other researchers have produced similar studies, such as Ishida et al. [135, 136], who performed a set of similar hydraulic experiments (the same in situ stress and flow rate) in the laboratory, using low and high viscous fluids (water/oil and supercritical/liquid $\mathrm{CO}_{2}$, resp.). The aim of their study was to investigate the effect of fluid viscosity to the breakdown pressure and compare the results from both studies. According to their findings they suggest that the supercritical $\mathrm{CO}_{2}\left(\mathrm{sc}-\mathrm{CO}_{2}\right)$ tends to initiate cracks which extend more three-dimensionally compared to the liquid $\mathrm{CO}_{2}\left(1-\mathrm{CO}_{2}\right)$ which generates cracks that extend in a fat plane. The comparison between the aforementioned results and the acoustic emissions from the use of water and oil were observed to be distributed in a narrower region. Furthermore, they concluded that the breakdown pressures were lower for the sc- $\mathrm{CO}_{2}$ than for the $1-\mathrm{CO}_{2}$, while the breakdown pressures produced from water and oil were significantly higher in comparison. Furthermore, Bruno [114] investigated the damage and the stress-induced permeability anisotropy in weakly cemented geological materials in the microscopic level. His results are well compared with the acoustic emissions of experimental data, with the reduction scale of the stress-induced permeability being dependent on the relationship between the amount of intergranular bonds and the stress levels. Specifically, the fluid permeability is reduced for both low and near hydrostatic stress levels, whereas for high deviatoric stress levels the flow channels increase affecting the induced permeability reduction. An overall anisotropy of the permeability is observed in the macroscopic level.

\section{Conclusions}

This paper provides a synopsis and an overview of the past and recent developments of hydraulic fracturing, its applications, its possible hazards, and the available computational methods for analysing this technique. Even though hydraulic fracturing has been extensively used for several decades as a method of exploiting energy sources, there is still requirement for further research developments due to the difficulty of understanding the complex underground mechanisms and the limitations of the available mathematical models.

A number of studies have focused on the possible hazardous behaviour of the fracking mechanism, both experimentally and numerically, with some of the topics including the contamination of shallow aquifers from flowback fluids, poor well integrity, the effect of active faults and leakage pathways, and induced seismicity. The outcome of these works has resulted in the development of advanced mathematical models that can be successfully applied in real world operations. The FEM has been widely used for numerous engineering problems. However, its limitations have led to other improved techniques, such as the DEM. The latter is an alternative approach that has become well recognized in this field since it is free from mesh sensitivity compared to the FEM and can provide more accurate reproductions of materials in terms of inhomogeneities and discontinuities.

Modelling the failure mechanism of hard rocks is a challenging task and the presence of preexisting discontinuities (fractures, faults) makes the problem even more complex. This paper presents a review on the available mathematical and computational models for simulating the mechanical behaviour of rock formations and fluid flow, as well as some critical studies and their fundamental outcome. Following the references provided in this paper, the readers can access the detailed discussion and formulation of a specific modelling approach. Even though scientists have developed advanced modelling techniques, such as the DEM, the XFEM, or the FDEM approaches, more research is required to fully understand the fracking mechanism. Areas such as the modelling of rocks with preexisting fractures under injection conditions in the microscale and the effect of fracture orientation and different injection and reservoir conditions, the transition between the models in different scales to improve the accuracy of modelling the field scale hydraulic fracturing process with the considerations and benefits of the microscopic mechanisms, and the influences of the chemical composition of the fracturing fluids are some of the topics that need to be addressed in the future.

\section{Conflict of Interests}

The authors declare that there is no conflict of interests regarding the publication of this paper. 


\section{Acknowledgments}

Marina Sousani would like to thank the School of Civil Engineering and the School of Chemical and Process Engineering, University of Leeds, for sponsoring this research.

\section{References}

[1] G. C. Howard and C. R. Fast, Hydraulic Fracturing: Core Issues \& Trends, vol. 5 of Mineral Law Series, Society of Petroleum Engineers, Houston, Tex, USA, 1970.

[2] M. J. Economides and T. Martin, Modern Fracturing-Enhancing Natural Gas Production, BJ Services Company, Houston, Tex, USA, 2007.

[3] P. Kasza and K. Wilk, "Completion of shale gas formations by hydraulic fracturing," Przemysl Chemiczny, vol. 91, no. 4, pp. 608-612, 2012.

[4] J. Adachi, E. Siebrits, A. Peirce, and J. Desroches, "Computer simulation of hydraulic fractures," International Journal of Rock Mechanics and Mining Sciences, vol. 44, no. 5, pp. 739-757, 2007.

[5] K. I.-I and Y. Sheng, "Modelling erosion control in oil production wells," World Academy of Science, Engineering \& Technology, vol. 4, no. 47, pp. 937-941, 2010.

[6] M. Smith, D. Campbell, E. Mackay, and D. Polson, $\mathrm{CO}_{2}$ Aquifer Storage Site Evaluation and Monitoring: Understanding the Challenges of $\mathrm{CO}_{2}$ Storage: Results of the CASSEM Project, Scottish Carbon Capture and Storage, Edinburgh, UK, 2012.

[7] M. J. Economides and K. G. Nolte, Reservoir Stimulation, John Wiley \& Sons, 2000.

[8] M. Mikkelsen, M. Jørgensen, and F. C. Krebs, "The teraton challenge. A review of fixation and transformation of carbon dioxide," Energy and Environmental Science, vol. 3, no. 1, pp. 4381, 2010.

[9] IPCC, Historical Overview of Climate Change Science, Intergovernmental Panel on Climate Change, chapter 1, 2007.

[10] DECC, The Carbon Plan: Delivering our Carbon Future, Department of Energy \& Climate Change, London, UK, 2011.

[11] European Commission, "Energy efficiency plan 2011," in Proceedings of the Communication from the Commission to the European Parliament, the Council, the European Economic and Social Committee and the Committee of the Regions (COM '11), p. 109, March 2011.

[12] European Commission, "Renewable energy: progressing towards the 2020 target," in Proceedings of the Communication from the Commission to the European Parliament and the Council (COM '11), vol. 31, 2011.

[13] IPCC, Climate Change 2007: Mitigation. Contribution of Working Group III to the Fourth Assessment Report of the Intergovernmental Panel on Climate Change, edited by B. Metz, O. R. Davidson, P. R. Bosch, P. Dave, L. A. Meyer, Cambridge University Press, New York, USA; Intergovernmental Panel on Climate Change, Cambridge, UK, 2007.

[14] International Energy Agency, Technology Roadmap: Carbon Capture and Storage, IEA Publications, Paris, France, 2013.

[15] J. Gibbins and H. Chalmers, "Carbon capture and storage," Energy Policy, vol. 36, no. 12, pp. 4317-4322, 2008.

[16] International Energy Agency, Gadgets and Gigawatts: Policy for Energy Efficient Electronics, IEA Publications, Paris, France, 2009.

[17] IPCC, Climate Change 2014: Mitigation of Climate Change, Intergovernmental Panel on Climate Change, Cambridge University Press, New York, NY, USA, 2014.
[18] The Global CCS Institute, The Global Status of CCS, The Global CCS Institute, Melbourne, Australia, 2014.

[19] B. Metz, O. R. Davidson, H. Coninck, M. Loos, and L. A. Meyer, IPCC. Carbon Dioxide Capture and Storage, Intergovernmental Panel on Climate Change, Cambridge University Press, New York, NY, USA, 2005.

[20] S. Holloway, "Carbon capture and geological storage," Philosophical Transactions of the Royal Society of London Series A, Containing Papers of a Mathematical or Physical Character, vol. 365, pp. 1095-1107, 2007.

[21] K. I.-I. Eshiet and Y. Sheng, "Carbon dioxide injection and associated hydraulic fracturing of reservoir formations," Environmental Earth Sciences, vol. 72, no. 4, pp. 1011-1024, 2014.

[22] BGS. DECC, The Carboniferous Bowland Shale Gas Study: Geology and Resource Estimation, Brirish Geological Survey (BGS), Department of Energy \& Climate Change (DECC), London, UK, 2013.

[23] C. Taylor and D. Lewis, Getting Shale Gas Working, vol. 6, Institue of Directors (IoD), 2013.

[24] Economic Affairs Committee, The Economic Impact on UK Energy Policy of Shale Gas and Oil, Economic Affairs Committee, London, UK, 2014.

[25] M. E. Parker, J. P. Meyer, and S. R. Meadows, "Carbon dioxide enhanced oil recovery injection operations technologies (poster presentation)," Energy Procedia, vol. 1, no. 1, pp. 3141-3148, 2009.

[26] S. Deng, H. Li, G. Ma, H. Huang, and X. Li, "Simulation of shaleproppant interaction in hydraulic fracturing by the discrete element method," International Journal of Rock Mechanics and Mining Sciences, vol. 70, pp. 219-228, 2014.

[27] B. van der Meer, "Carbon dioxide storage in natural gas reservoirs," Oil \& Gas Science and Technology, vol. 60, no. 3, pp. 527536, 2005.

[28] C. Khan, R. Amin, and G. Madden, "Carbon dioxide injection for enhanced gas recovery and storage (reservoir simulation)," Egyptian Journal of Petroleum, vol. 22, no. 2, pp. 225-240, 2013.

[29] M. Blunt, F. J. Fayers, and F. M. Orr Jr., "Carbon dioxide in enhanced oil recovery," Energy Conversion and Management, vol. 34, no. 9-11, pp. 1197-1204, 1993.

[30] H. Jin, L. Gao, L. Sheng, and R. Porter, Supporting early Carbon Capture Utilisation and Storage Development in Non-Power Industrial Sectors, Shaanxi Province, China, vol. 12, Centre for Low Carbon Futures, York, UK, 2012.

[31] E. Fjaer, R. M. Holt, A. M. Raaen, R. Risnes, and P. Horsrud, Petroleum Related Rock Mechanics. Developments in Petroleum Science, vol. 53, Elsevier, Amsterdam, The Netherlands, 2008.

[32] S. J. Wilkins and S. J. Naruk, "Quantitative analysis of slipinduced dilation with application to fault seal," AAPG Bulletin, vol. 91, no. 1, pp. 97-113, 2007.

[33] J. Kaldi, R. Daniel, E. Tenthorey et al., Caprock Systems for Geological Storage, vol. 1, EAGHG, Cheltenham, UK, 2011.

[34] A. Kissinger, R. Helmig, A. Ebigbo et al., "Hydraulic fracturing in unconventional gas reservoirs: risks in the geological system, part 2," Environmental Earth Sciences, vol. 70, no. 8, pp. 38553873, 2013.

[35] B. C. Gordalla, U. Ewers, and F. H. Frimmel, "Hydraulic fracturing: a toxicological threat for groundwater and drinkingwater?" Environmental Earth Sciences, vol. 70, no. 8, pp. 38753893, 2013.

[36] J. Riedl, S. Rotter, S. Faetsch, M. Schmitt-Jansen, and R. Altenburger, "Proposal for applying a component-based mixture approach for ecotoxicological assessment of fracturing fluids," 
Environmental Earth Sciences, vol. 70, no. 8, pp. 3907-3920, 2013.

[37] O. Olsson, D. Weichgrebe, and K.-H. Rosenwinkel, "Hydraulic fracturing wastewater in Germany: composition, treatment, concerns," Environmental Earth Sciences, vol. 70, no. 8, pp. 3895-3906, 2013.

[38] T. Lange, M. Sauter, M. Heitfeld et al., "Hydraulic fracturing in unconventional gas reservoirs: risks in the geological system part 1," Environmental Earth Sciences, vol. 70, no. 8, pp. 38393853, 2013.

[39] COM, Exploration and Production of Hydrocarbons (Such as Shale Gas) Using High Volume Hydraulic Fracturing in the EU, European Commission, Brussels, Belgium, 2014.

[40] C. Ewen, D. Borchardt, R. Hammerbacher, and S. Richter, Hydrofracking Risk Assessment, Panel of Experts, ExxonMobil Production Deutschland, 2012.

[41] V. Sarhosis and Y. Sheng, "Identification of material parameters for low bond strength masonry," Engineering Structures, vol. 60, pp. 100-110, 2014.

[42] M. E. Hanson, G. D. Anderson, and R. J. Shaffer, "Theoretical and experimental research on hydraulic fracturing," Journal of Energy Resources Technology, vol. 102, no. 2, pp. 92-98, 1980.

[43] S. Marina, E. K. Imo-Imo, I. Derek, P. Mohamed, and S. Yong, "Modelling of hydraulic fracturing process by coupled discrete element and fluid dynamic methods," Environmental Earth Sciences, vol. 72, no. 9, pp. 3383-3399, 2014.

[44] K. I. Eshiet, Y. Sheng, and J. Ye, "Microscopic modelling of the hydraulic fracturing process," Environmental Earth Sciences, vol. 68, no. 4, pp. 1169-1186, 2013.

[45] D. O. Potyondy and P. A. Cundall, "A bonded-particle model for rock," International Journal of Rock Mechanics \& Mining Sciences, vol. 41, no. 8, pp. 1329-1364, 2004.

[46] L. Bortolan Neto and A. Kotousov, "Residual opening of hydraulically stimulated fractures filled with granular particles," Journal of Petroleum Science and Engineering, vol. 100, pp. 2429, 2012.

[47] P. A. Cundall and O. D. L. Strack, "Discrete numerical model for granular assemblies," Geotechnique, vol. 29, no. 1, pp. 47-65, 1979.

[48] M. Sousani, D. Ingham, M. Pourkashanian, Y. Sheng, and I.I. K. Eshiet, "Simulation of the hydraulic fracturing process of fractured rocks by the discrete element method," Environmental Earth Sciences, vol. 73, no. 12, pp. 8451-8469, 2015.

[49] A. Lisjak and G. Grasselli, "A review of discrete modeling techniques for fracturing processes in discontinuous rock masses," Journal of Rock Mechanics and Geotechnical Engineering, vol. 6, no. 4, pp. 301-314, 2014.

[50] N. Cho, C. D. Martin, and D. C. Sego, "A clumped particle model for rock," International Journal of Rock Mechanics and Mining Sciences, vol. 44, no. 7, pp. 997-1010, 2007.

[51] D. O. Potyondy, "A flat-jointed bonded-particle material for hard rock," in Proceedings of the 46th US Rock Mechanics/Geomechanics Symposium, Chicago, Ill, USA, January 2012.

[52] D. Mas Ivars, Bonded particle model for jointed rock, KTH Royal Institute of Technology, Stockolm, Sweden, 2010.

[53] D. Mas Ivars, M. E. Pierce, C. Darcel et al., "The synthetic rock mass approach for jointed rock mass modelling," International Journal of Rock Mechanics and Mining Sciences, vol. 48, no. 2, pp. 219-244, 2011.

[54] J. Kozicki and F. V. Donzé, "A new open-source software developed for numerical simulations using discrete modeling methods," Computer Methods in Applied Mechanics and Engineering, vol. 197, no. 49-50, pp. 4429-4443, 2008.

[55] J. Kozicki and F. V. Donzé, "YADE-OPEN DEM: an opensource software using a discrete element method to simulate granular material," Engineering Computations, vol. 26, no. 7, pp. 786-805, 2009.

[56] L. Scholtès and F.-V. Donzé, "Modelling progressive failure in fractured rock masses using a 3D discrete element method," International Journal of Rock Mechanics and Mining Sciences, vol. 52, pp. 18-30, 2012.

[57] L. Scholtès and F.-V. Donzé, "A DEM model for soft and hard rocks: role of grain interlocking on strength," Journal of the Mechanics and Physics of Solids, vol. 61, no. 2, pp. 352-369, 2013.

[58] L. Scholtès, F.-V. Donzé, and M. Khanal, "Scale effects on strength of geomaterials, case study: coal," Journal of the Mechanics and Physics of Solids, vol. 59, no. 5, pp. 1131-1146, 2011.

[59] B. Harthong, L. Scholtès, and F.-V. Donzé, "Strength characterization of rock masses, using a coupled DEM-DFN model," Geophysical Journal International, vol. 191, no. 2, pp. 467-480, 2012.

[60] S. C. Fan, Y. Y. Jiao, and J. Zhao, "On modelling of incident boundary for wave propagation in jointed rock masses using discrete element method," Computers and Geotechnics, vol. 31, no. 1, pp. 57-66, 2004.

[61] X. B. Zhao, J. Zhao, J. G. Cai, and A. M. Hefny, "UDEC modelling on wave propagation across fractured rock masses," Computers and Geotechnics, vol. 35, no. 1, pp. 97-104, 2008.

[62] L. J. Lorig and P. A. Cundall, "Modeling of reinforced concrete using the distinct element method," in Fracture of Concrete and Rock, S. Shah and S. Swartz, Eds., pp. 276-287, Springer, New York, NY, USA, 1989.

[63] M. Christianson, M. Board, and D. Rigby, "UDEC simulation of triaxial testing of lithophysal tuff," in Proceedings of the 41st US Symposium on Rock Mechanics (USRMS '06), Golden, Colo, USA, June 2006.

[64] B. Damjanac, M. Board, M. Lin, D. Kicker, and J. Leem, "Mechanical degradation of emplacement drifts at Yucca Mountain-a modeling case study. Part II: lithophysal rock," International Journal of Rock Mechanics and Mining Sciences, vol. 44, no. 3, pp. 368-399, 2007.

[65] G. Shi and R. E. Goodman, "Discontinuous deformation analysis-a new method for computing stress, strain and sliding of block systems," in Proceedings of the 29th US Symposium on Rock Mechanics (USRMS '88), Minneapolis, Minn, USA, 1988.

[66] C. A. Tang and H. Y. Lu, "The DDD method based on combination of RFPA," in Frontiers of Discontinuous Numerical Methods and Practical Simulations in Engineering and Disaster Prevention, G. Chen, Y. Ohnishi, L. Zheng, and T. Sasaki, Eds., pp. 105-112, CRC Press, 2013.

[67] C. Tang, "Numerical simulation of progressive rock failure and associated seismicity," International Journal of Rock Mechanics and Mining Sciences, vol. 34, no. 2, pp. 249-261, 1997.

[68] T. Belytschko and T. Black, "Elastic crack growth in finite elements with minimal remeshing," International Journal for Numerical Methods in Engineering, vol. 45, no. 5, pp. 601-620, 1999.

[69] N. Moës, J. Dolbow, and T. Belytschko, "A finite element method for crack growth without remeshing," International Journal for Numerical Methods in Engineering, vol. 46, no. 1, pp. 131-150, 1999. 
[70] V. Giamundo, V. Sarhosis, G. P. Lignola, Y. Sheng, and G. Manfredi, "Evaluation of different computational modelling strategies for the analysis of low strength masonry structures," Engineering Structures, vol. 73, pp. 160-169, 2014.

[71] Itasca Consulting Group, Lagrangian Analysis of Continua (FLAC), ICG, Minneapolis, Minn, USA, 5th edition, 2005.

[72] J.-H. Song, P. Lea, and J. Oswald, "Explicit dynamic finite element method for predicting implosion/explosion induced failure of shell structures," Mathematical Problems in Engineering, vol. 2013, Article ID 957286, 11 pages, 2013.

[73] P. M. A. Areias and T. Belytschko, "Analysis of three-dimensional crack initiation and propagation using the extended finite element method," International Journal for Numerical Methods in Engineering, vol. 63, no. 5, pp. 760-788, 2005.

[74] Q. Duan, J.-H. Song, T. Menouillard, and T. Belytschko, "Element-local level set method for three-dimensional dynamic crack growth," International Journal for Numerical Methods in Engineering, vol. 80, no. 12, pp. 1520-1543, 2009.

[75] Y. Cai, X. Zhuang, and C. Augarde, "A new partition of unity finite element free from the linear dependence problem and possessing the delta property," Computer Methods in Applied Mechanics and Engineering, vol. 199, no. 17-20, pp. 1036-1043, 2010.

[76] Rockfield Software, ELFEN 2D/3D Numerical Modelling Package, Rockfield Software, Swansea, UK, 2004.

[77] A. Munjiza, K. R. F. Andrews, and J. K. White, "Combined single and smeared crack model in combined finite-discrete element analysis," International Journal for Numerical Methods in Engineering, vol. 44, no. 1, pp. 41-57, 1999.

[78] A. Munjiza, The Combined Finite-Discrete Element Method, John Wiley \& Sons, Chichester, UK, 2004.

[79] D. R. J. Owen and Y. T. Feng, "Parallelised finite/discrete element simulation of multi-fracturing solids and discrete systems," Engineering Computations, vol. 18, no. 3-4, pp. 557-576, 2001.

[80] J. Rutqvist, J. Birkholzer, F. Cappa, and C.-F. Tsang, "Estimating maximum sustainable injection pressure during geological sequestration of $\mathrm{CO}_{2}$ using coupled fluid flow and geomechanical fault-slip analysis," Energy Conversion and Management, vol. 48, no. 6, pp. 1798-1807, 2007.

[81] K. Walton, "The effective elastic moduli of a random packing of spheres," Journal of the Mechanics and Physics of Solids, vol. 35, no. 2, pp. 213-226, 1987.

[82] S. Chen and G. D. Doolen, "Lattice boltzmann method for fluid flows," Annual Review of Fluid Mechanics, vol. 30, pp. 329-364, 1998.

[83] S. Dong, "Direct numerical simulation of turbulent TaylorCouette flow," Journal of Fluid Mechanics, vol. 587, pp. 373-393, 2007.

[84] P. Moin and K. Mahesh, "Direct numerical simulation: a tool in turbulence research," Annual Review of Fluid Mechanics, vol. 30, pp. 539-578, 1998.

[85] D. F. Boutt, B. K. Cook, B. J. O. L. McPherson, and J. R. Williams, "Direct simulation of fluid-solid mechanics in porous media using the discrete element and lattice-Boltzmann methods," Journal of Geophysical Research: Solid Earth, vol. 112, no. 10, pp. $1-13,2007$.

[86] Y. Tsuji, T. Kawaguchi, and T. Tanaka, "Discrete particle simulation of two-dimensional fluidized bed," Powder Technology, vol. 77, no. 1, pp. 79-87, 1993.

[87] B. H. Xu and A. B. Yu, "Numerical simulation of the gas-solid flow in a fluidized bed by combining discrete particle method with computational fluid dynamics," Chemical Engineering Science, vol. 52, no. 16, pp. 2785-2809, 1997.

[88] R. T. Ewy, G. W. Cook, and L. R. Myer, "Hollow cylinder tests for studying fracture around underground openings," in Proceedings of the 29th US Symposium on Rock Mechanics (USRMS '88), Minneapolis, Minn, USA, June 1988.

[89] M. E. Hanson, G. D. Anderson, R. J. Shaffer, and L. D. Thorson, "Some effects of stress, friction, and fluid flow on hydraulic fracturing," Society of Petroleum Engineers Journal, vol. 22, no. 3, 1982.

[90] P. A. Cundall, "A computer model for simulating progressive, large-scale movements in blocky rock systems," in Proceedings of the Symposium of International Society of Rock Mechanics, vol. 1, Nancy, France, 1971.

[91] S. C. Blair, R. K. Thorpe, F. E. Heuze, and R. J. Shaffer, "Laboratory observations of the effect of geologic discontinuities on hydrofracture propagation," in Proceedings of the 30th US Symposium on Rock Mechanics (USRMS '98), Morgantown, WVa, USA, January 1989.

[92] Q. Fang and Y. Li, "Exhaustive brine production and complete $\mathrm{CO}_{2}$ storage in Jianghan Basin of China," Environmental Earth Sciences, vol. 72, no. 5, pp. 1541-1553, 2014.

[93] I. Matsunaga, H. Kobayashi, S. Sasaki, and T. Ishida, "Studying hydraulic fracturing mechanism by laboratory experiments with acoustic emission monitoring," International Journal of Rock Mechanics and Mining Sciences \& Geomechanics Abstracts, vol. 30, no. 7, pp. 909-912, 1993.

[94] M. Zeidouni, J.-P. Nicot, and S. D. Hovorka, "Monitoring abovezone temperature variations associated with $\mathrm{CO}_{2}$ and brine leakage from a storage aquifer," Environmental Earth Sciences, vol. 72, no. 5, pp. 1733-1747, 2014.

[95] X. Zhuang, C. E. Augarde, and K. M. Mathisen, "Fracture modeling using meshless methods and level sets in 3D: framework and modeling," International Journal for Numerical Methods in Engineering, vol. 92, no. 11, pp. 969-998, 2012.

[96] X. Zhuang, C. Augarde, and S. Bordas, "Accurate fracture modelling using meshless methods, the visibility criterion and level sets: formulation and 2D modelling," International Journal for Numerical Methods in Engineering, vol. 86, no. 2, pp. 249268, 2011.

[97] G. Zi and T. Belytschko, "New crack-tip elements for XFEM and applications to cohesive cracks," International Journal for Numerical Methods in Engineering, vol. 57, no. 15, pp. 2221-2240, 2003.

[98] H. Zhu, X. Zhuang, Y. Cai, and G. Ma, "High rock slope stability analysis using the enriched meshless shepard and least squares method," International Journal of Computational Methods, vol. 8, no. 2, pp. 209-228, 2011.

[99] B. C. Haimson, "Hydraulic fracturing and rock characterization," International Journal of Rock Mechanics and Mining Sciences, vol. 41, supplement 1, pp. 188-194, 2004.

[100] F. Hamidi and A. Mortazavi, "A new three dimensional approach to numerically model hydraulic fracturing process," Journal of Petroleum Science and Engineering, vol. 124, pp. 451467, 2014.

[101] N. Nagel, I. Gil, M. Sanchez-Nagel, and B. Damjanac, "Simulating hydraulic fracturing in real fractured rocks-overcoming the limits of Pseudo3D models," in Proceedings of the SPE Hydraulic Fracturing Technology Conference, The Woodlands, Texas, USA, January 2011.

[102] A. Al-Busaidi, J. F. Hazzard, and R. P. Young, "Distinct element modeling of hydraulically fractured Lac du Bonnet granite," 
Journal of Geophysical Research: Solid Earth, vol. 110, Article ID B06302, 2005.

[103] T. Wang, W. Zhou, J. Chen, X. Xiao, Y. Li, and X. Zhao, "Simulation of hydraulic fracturing using particle flow method and application in a coal mine," International Journal of Coal Geology, vol. 121, pp. 1-13, 2014.

[104] P. Papanastasiou, "Hydraulic fracture closure in a pressuresensitive elastoplastic medium," International Journal of Fracture, vol. 103, no. 2, pp. 149-161, 2000.

[105] D. B. van Dam, C. J. de Pater, and R. Romijn, "Analysis of hydraulic fracture closure in laboratory experiments," SPE Production \& Facilities, vol. 15, no. 3, pp. 151-158, 2000.

[106] A. Khanna, A. Kotousov, J. Sobey, and P. Weller, "Conductivity of narrow fractures filled with a proppant monolayer," Journal of Petroleum Science and Engineering, vol. 100, pp. 9-13, 2012.

[107] M. C. Vincent, "Proving it-a review of 80 published field studies demonstrating the importance of increased fracture conductivity," in Proceedings of the SPE Annual Technical Conference and Exhibition, San Antonio, Tex, USA, 2002.

[108] J. S. Yoon, A. Zang, and O. Stephansson, "Numerical investigation on optimized stimulation of intact and naturally fractured deep geothermal reservoirs using hydro-mechanical coupled discrete particles joints model," Geothermics, vol. 52, pp. 165184, 2014.

[109] J. C. Jaeger, N. G. W. Cook, and R. W. Zimmerman, Fundamentals of Rock Mechanics, Wiley-Blackwell, Oxford, UK, 4th edition, 2007.

[110] X. Zhang, N. Last, W. Powrie, and R. Harkness, "Numerical modelling of wellbore behaviour in fractured rock masses," Journal of Petroleum Science and Engineering, vol. 23, no. 2, pp. 95-115, 1999.

[111] R. M. Holt, "Permeability reduction induced by a non-hydrostatic stress field," SPE Formation Evaluation, vol. 5, no. 4, pp. 444-448, 1990.

[112] S. Bachu and B. Bennion, "Effects of in-situ conditions on relative permeability characteristics of $\mathrm{CO}_{2}$-brine systems," Environmental Geology, vol. 54, no. 8, pp. 1707-1722, 2008.

[113] M. J. Bouteca, J. P. Sarda, and O. Vincke, "Constitutive law for permeability evolution of sandstones during depletion," in Proceedings of the SPE International Symposium on Formation Damage Control, Lafayette, La, USA, 2000.

[114] M. S. Bruno, "Micromechanics of stress-induced permeability anisotropy and damage in sedimentary rock," Mechanics of Materials, vol. 18, no. 1, pp. 31-48, 1994.

[115] S. L. Bryant, P. R. King, and D. W. Mellor, "Network model evaluation of permeability and spatial correlation in a real random sphere packing," Transport in Porous Media, vol. 11, no. 1, pp. 53-70, 1993.

[116] J. Desroches and M. Thiercelin, "Modelling the propagation and closure of micro-hydraulic fractures," International Journal of Rock Mechanics and Mining Sciences \& Geomechanics Abstracts, vol. 30, no. 7, pp. 1231-1234, 1993.

[117] D. Bigoni and E. Radi, "Mode I crack propagation in elasticplastic pressure-sensitive materials," International Journal of Solids and Structures, vol. 30, no. 7, pp. 899-919, 1993.

[118] D. B. van Dam, C. J. de Pater, and R. Romijn, "Analysis of hydraulic fracture closure in laboratory experiments," $S P E$ Production \& Facilities, vol. 15, no. 3, pp. 151-158, 2000.

[119] N. R. F. Warpinski, P. T. F. Branagan, K. D. F. Mahrer, S. L. F. Wolhart, and Z. A. F. Moschovidis, "Microseismic monitoring of the Mounds drill cuttings injection tests," in Proceedings of the 37th US Symposium on Rock Mechanics (USRMS '99), Vail, Colo, USA, 1999.

[120] A. S. P. Green, R. Baria, A. Madge, and R. Jones, "Faultplane analysis of microseismicity induced by fluid injections into granite," Geological Society, London, Engineering Geology Special, vol. 5, no. 1, pp. 415-422, 1988.

[121] H. Wang, E. Wang, and K. Tian, "A model coupling discrete and continuum fracture domains for groundwater flow in fractured media," Journal of Hydraulic Research, vol. 42, supplement 1, pp. 45-52, 2004.

[122] Q. Wu, Y. Liu, D. Liu, and W. Zhou, "Prediction of floor water inrush: the application of GIS-based AHP vulnerable index method to donghuantuo coal mine, China," Rock Mechanics and Rock Engineering, vol. 44, no. 5, pp. 591-600, 2011.

[123] B. Zhu, Q. Wu, J. Yang, and T. Cui, "Study of pore pressure change during mining and its application on water inrush prevention: a numerical simulation case in Zhaogezhuang coalmine, China," Environmental Earth Sciences, vol. 71, no. 5, pp. 2115-2132, 2014.

[124] Y. Huang, Z. Zhou, J. Wang, and Z. Dou, "Simulation of groundwater flow in fractured rocks using a coupled model based on the method of domain decomposition," Environmental Earth Sciences, vol. 72, no. 8, pp. 2765-2777, 2014.

[125] S. P. Neuman, "Trends, prospects and challenges in quantifying flow and transport through fractured rocks," Hydrogeology Journal, vol. 13, no. 1, pp. 124-147, 2005.

[126] A. Woodbury and K. Zhang, "Lanczos method for the solution of groundwater flow in discretely fractured porous media," Advances in Water Resources, vol. 24, no. 6, pp. 621-630, 2001.

[127] B. Berkowitz, "Characterizing flow and transport in fractured geological media: a review," Advances in Water Resources, vol. 25, no. 8-12, pp. 861-884, 2002.

[128] M. Sousani, Modeling of Hydraulic Fracturing in Rocks: A Multiscale and Fluid-Solid Coupling Approach, University of Leeds, Leeds, UK, 2015.

[129] D. Martinez, Fundamental hydraulic fracturing concepts for poorly consolitated formations [Ph.D. thesis], University of Oklahoma, Ann Arbor, Mich, USA, 2012.

[130] H. Shimizu, S. Murata, and T. Ishida, "The distinct element analysis for hydraulic fracturing in hard rock considering fluid viscosity and particle size distribution," International Journal of Rock Mechanics and Mining Sciences, vol. 48, no. 5, pp. 712-727, 2011.

[131] H. Shimizu, S. Murata, T. Ito, and T. Ishida, "The distinct element analysis for hydraulic fracturing in unconsolidated sand considering fluid viscosity," in Proceedings of the 7th Asian Rock Mechanics Symposium, January 2012.

[132] H. Shimizu, S. Murata, and T. Ishida, "The distinct element analysis for hydraulic fracturing considering the fluid viscosity," in Proceedings of the 43rd US Rock Mechanics Symposium \& 4th US-Canada Rock Mechanics Symposium, Asheville, NC, USA, June 2009.

[133] T. Ishida, S. Sasaki, I. Matsunaga, Q. Chen, and Y. Mizuta, "Effect of grain size in granitic rocks on hydraulic fracturing mechanism," in Trends in Rocks Mechanics: Proceedings of Sessions of Geo-Denver, GSP, Ed., pp. 128-139, American Society of Civil Engineers, Denver, Colo, USA, 2000.

[134] T. Ishida, "Acoustic emission monitoring of hydraulic fracturing in laboratory and field," Construction and Building Materials, vol. 15, no. 5-6, pp. 283-295, 2001. 
[135] T. Ishida, K. Aoyagi, T. Niwa et al., "Acoustic emission monitoring of hydraulic fracturing laboratory experiment with supercritical and liquid $\mathrm{CO}_{2}$," Geophysical Research Letters, vol. 39, no. 16, Article ID L16309, 2012.

[136] T. Ishida, Q. Chen, Y. Mizuta, and J.-C. Roegiers, "Influence of fluid viscosity on the hydraulic fracturing mechanism," Journal of Energy Resources Technology, vol. 126, no. 3, 11 pages, 2004.

[137] SCCS, Opportunities for $\mathrm{CO}_{2}$ Storage Around Scotland: An Integraded Research Study, Scottish Centre for Carbon Storage, Scotprint, Edinburgh, UK, 2009.

[138] Royal Society R, Shale Gas Extraction in the UK: A Review of Hydraulic Fracturing, DES2597, The Royal Society, The Royal Academy of Engineering, London, UK, 2012.

[139] Itasca Consulting Group, Theory and Background 2: Contact models, ICG, Minneapolis, Minn, USA, 2008. 


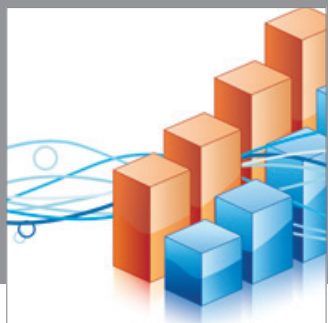

Advances in

Operations Research

mansans

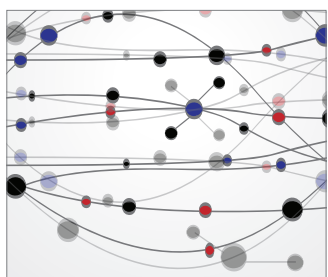

The Scientific World Journal
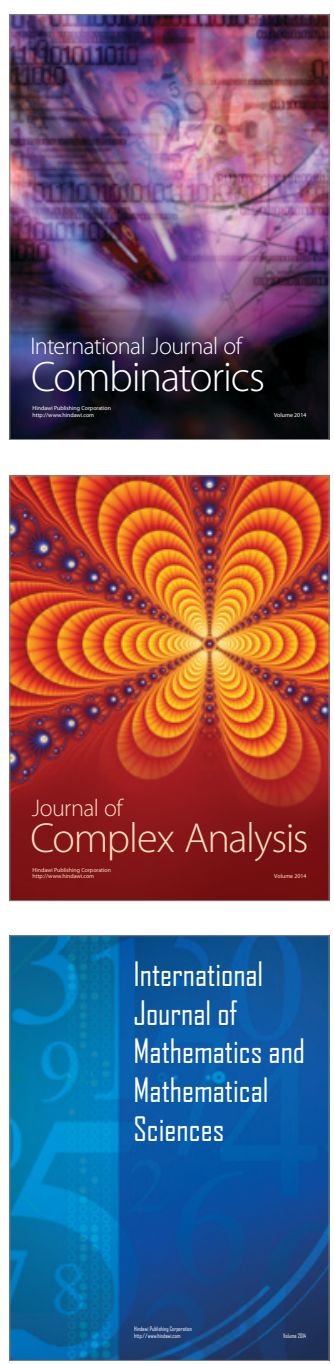
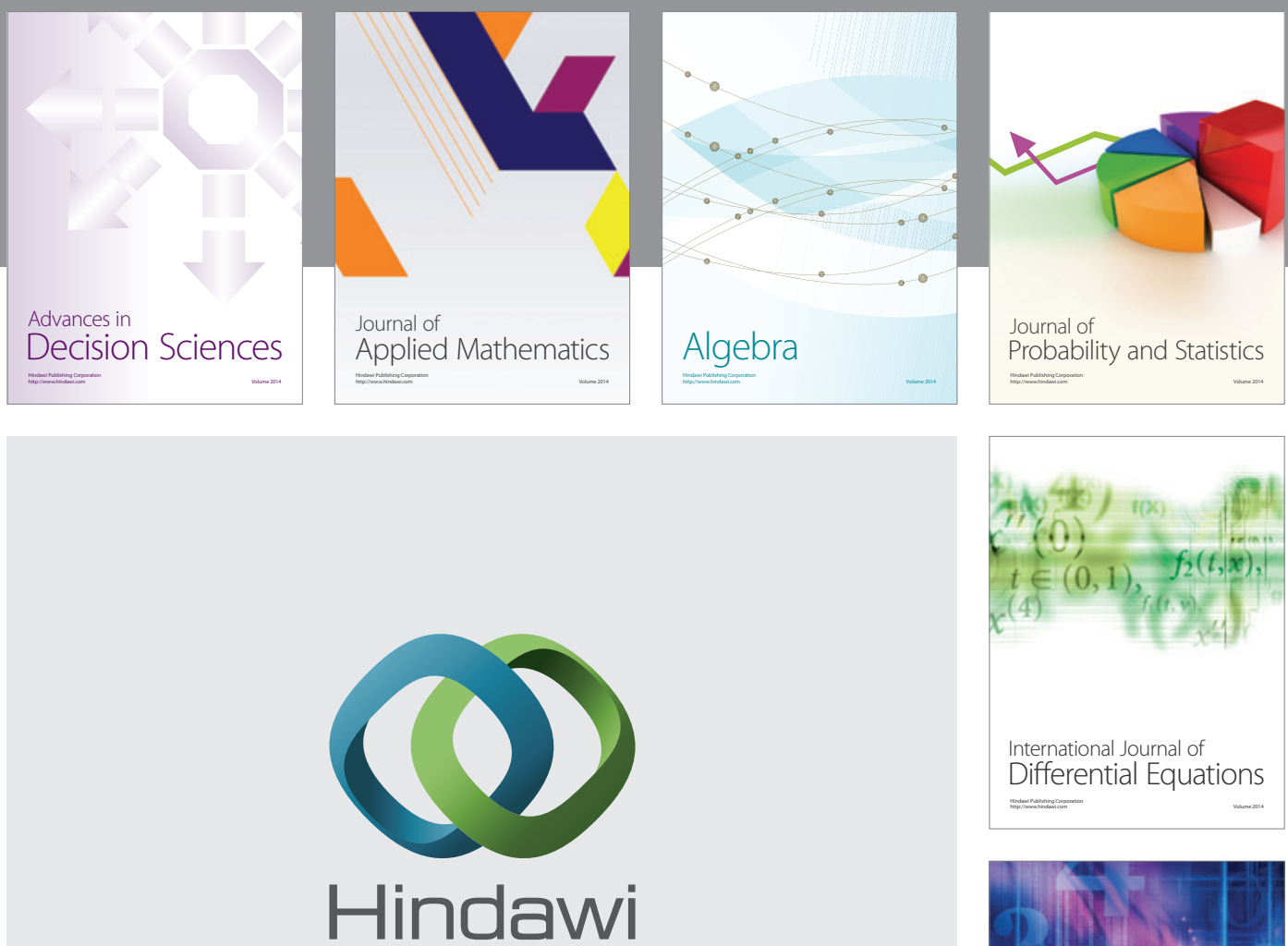

Submit your manuscripts at http://www.hindawi.com
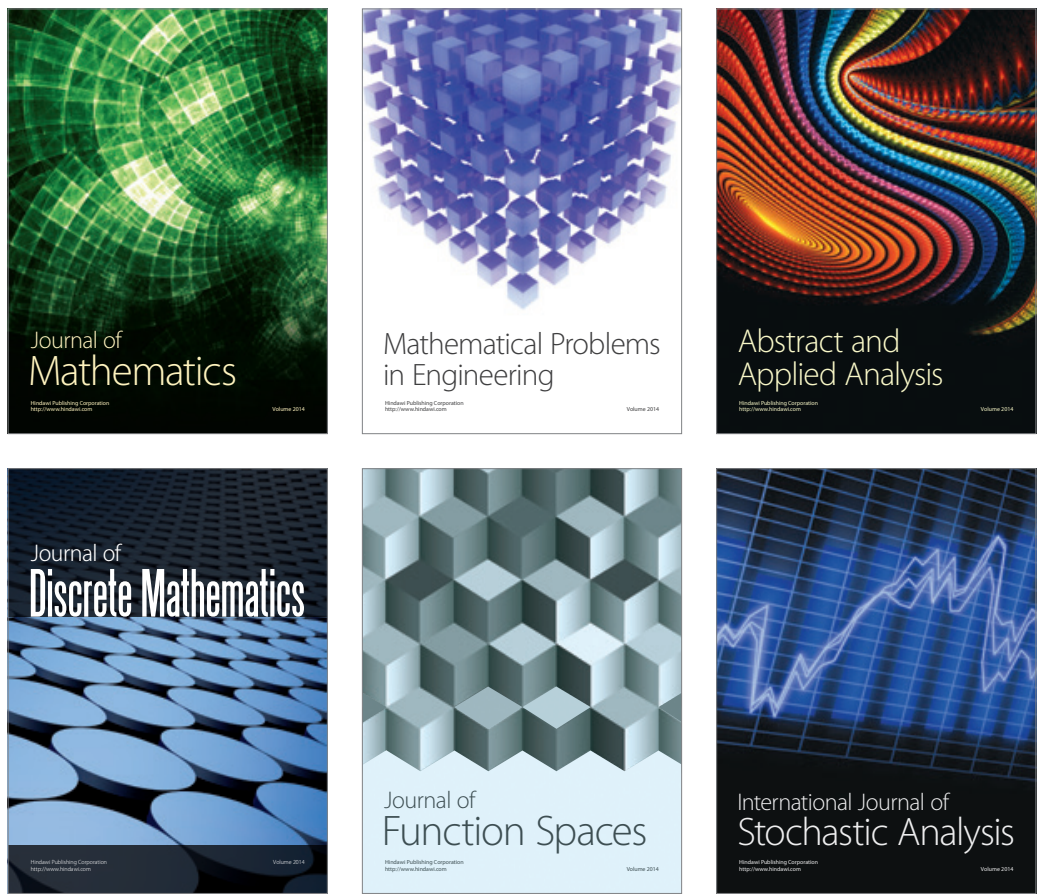

Journal of

Function Spaces

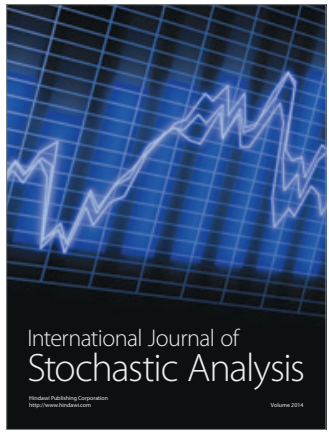

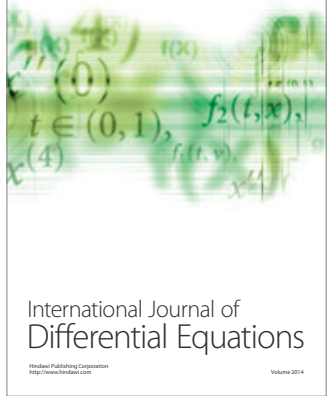
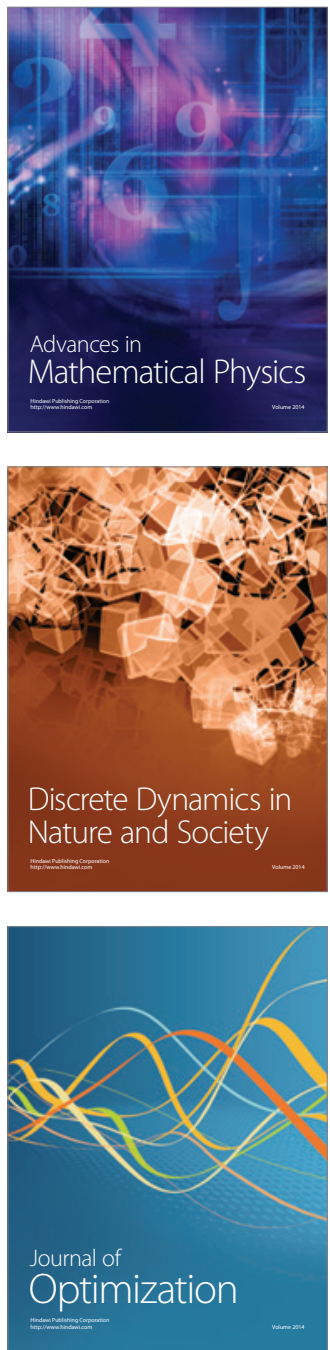